http://dx.doi.org/10.11646/phytotaxa.135.1.5

\title{
Taxonomic position and identity of Stemodia scoparioides (Gratiolae, Plantaginaceae)
}

\author{
MARIA DE LAS MERCEDES SOSA \& MASSIMILIANO DEMATTEIS \\ Instituto de Botánica del Nordeste (UNNE-CONICET), Casilla de Correo 209, 3400 Corrientes, Argentina; \\ E-mail:mdlmsvg@yahoo.com.ar; mdematteis@agr.unne.edu.ar
}

\begin{abstract}
In recent floristic and taxonomic studies, Stemodia scoparioides (Gratiolae, Plantaginaceae) has been considered a synonym of $S$. lanceolata or a synonym of $S$. stricta. However, a detailed analysis of the type material and additional specimens clearly indicates that this is a different species, which can be distinguished by the aspect of the plants, the size of the leaves, the shape of the blades, and the length of the corollas. Consequently, in this contribution Stemodia scoparioides is resurrected from the synonymy as an independent species based on the analysis of morphological features. Additionally, complete description (including the pollen grains), geographic distribution, ecological observations, and a key to distinguish the related species are also reported, together with an illustration of $S$. scoparioides.
\end{abstract}

\section{Introduction}

Stemodia Linnaeus (1759: 1118) belongs to the tribe Gratiolae Bentham (1846:340) of the large plant family Plantaginaceae Jussieu (1789: 89) and comprises about 49 species (Dawson 1968, Turner \& Cowan 1993, 1994, Barringer \& Burger 2000). For the New World 29 species are recognized, 16 of them are exclusive from South America (Turner \& Cowan 1994). In southern South America nine species have been reported, but just Stemodia verticillata (Miller 1768: 5) Hassler (1909: 110) has a wide distribution, while the remaining eight taxa are typically endemic of Argentina, Paraguay, Uruguay, extreme south of Bolivia, and southern Brazil.

Stemodia scoparioides Hassl. ex Minod (1918: 208) was validly published by Minod (1918) based on material collected by Hassler near the Apa river in northern Paraguay. The author distinguished the species from its allied taxa by the leaf shape and the general appearance of the plant. According to Minod (1918) this species differs from the rest of the genus by having smaller leaves and more abundant branching ("C $C$ 'est, de tout le genre, l'espèce qui'possède lesles feuilles les plus reduites et la ramification la plus abondante"). However, Turner \& Cowan (1994) considered Stemodia scoparioides as a synonym of S. lanceolata Benth. in Bentham (1846: 384), while Souza (2008) and Souza \& Giulietti (2009) considered S. scoparioides as a synonym of $S$. stricta Chamisso \& Schlechtendal (1828: 10). The main goal of this work is to clarify this situation, if Stemodia scoparioides is a synonym of S. lanceolata or S. stricta or if it is an independent species.

\section{Materials and Methods}

This study was based on morphological analysis of the type specimens and additional material deposited at BM, CTES, G, G-DEL, and K.

Additionally, a comparative study of the pollen grains of the involved species was conducted. Pollen grains were acetolyzed according to the procedure suggested by Erdtman (1960). For the observation with the light microscope (LM) the pollen samples were mounted in glycerin jelly on glass slides, sealed with paraffin 